\title{
PERFIS ATMOSFÉRICOS DA CAVERNA SANTANA (PETAR, IPORANGA- SP): CONTRIBUIÇÕES À CLASSIFICAÇÃO ESPELEOCLIMÁTICA E AO MANEJO TURÍSTICO
}

\author{
LOBO, Heros Augusto S.
}

\begin{abstract}
Resumo
As cavernas são detentoras de características ambientais que as diferenciam de outros ambientes, das quais se destaca a sua atmosfera, com mínimas influências solares diretas e movimentação gasosa relativamente baixa, configurando o espeleoclima. As investigações desta atmosfera vêm sendo feito, mundialmente, de duas formas distintas: a) registros de baixa densidade amostral espacial por períodos mais longos de tempo (monitoramento); e b) registros espaciais densos e temporalmente variáveis (perfil). O presente estudo apresenta os resultados de perfis atmosféricos realizados na caverna Santana, focados na classificação ambiental e na obtenção de contribuições ao manejo turístico. Os resultados demonstraram que as variáveis umidade relativa do ar e pressão atmosférica não ofereceram contribuições para ambas as finalidades quando registradas em perfil. Por outro lado, a temperatura do ar e a concentração de $\mathrm{CO}_{2}$ permitiram classificar a caverna Santana como uma warm trap, com acúmulo de massas de ar mais quentes em suas galerias superiores. Além disso, possibilitaram a compreensão de que o turismo praticado na caverna Santana não gera impactos significativos, sistêmicos ou amplos no ambiente, ficando estes circunscritos apenas aos trechos diretamente afetados pela visitação.
\end{abstract}

Palavras-Chave: Monitoramento espeleoclimático; espeleoturismo; microclima; manejo turístico.

ATMOSPHERIC PROFILES IN THE SANTANA CAVE
CONTRIBUTIONS TO THE SPELEOCLIMATIC CLASSIFICATION AND TO THORANGA-SP):
MANAGEMENT

Abstract - Caves have characteristics that are different from any other environments on earth, with special emphasis to its atmosphere, with restricted direct influences of the sun and air flow, that sets the speleoclimate. In a worldwide basis, the research of this atmosphere considers two different ways: a) registers of samples with low spatial density in a long term basis (monitoring); and b) dense spatial patterns of register, with great time-varying (profile). The present study shows the results of the atmospheric profile in the Santana cave, focused in the classification of the environment and in contributing to the tourist management. The results show that the relative humidity and atmospheric pressure do not contribute to these goals when these variables are registered in a profile mode. However, both the air temperature and the $\mathrm{CO}_{2}$ allow the classification of the Santana cave as a warm trap, with the accumulation of hot air in the upper galleries. Moreover, they make possible the comprehension that the tourism practices in the Santana cave did not generate significant, systemic or extensive impacts in the cave environment, concentrating the impacts only in the tourist area of the cave.

Keywords: Climate Monitoring; Show Caves; Microclimate; Management.

\section{INTRODUÇÃo}

As cavernas são espaços naturais diferenciados que abrigam condições únicas de variação atmosférica, se diferenciando dos microclimas de superfície. A quase total ausência de incidência solar direta - limitada às proximidades dos acessos superficiais, como claraboias e pórticos de entrada - está entre os fatores mais preponderantes para esta especificidade. Mas o confinamento espacial, com a presença de barreiras físicas que atenuam ou até mesmo 
impedem a circulação atmosférica, também é um fator de suma importância para a caracterização do espeleoclima. Em linhas gerais, trata-se de uma escala de estudos inferior ao clima e mesmo ao microclima, marcada por uma maior estabilidade higrotérmica em zonas mais profundas dos ambientes cavernícolas. De um modo geral, os estudos espeleoclimáticos ainda são pouco aprofundados no Brasil, com a maioria dos trabalhos com enfoque espacial pontual e baixa extensão temporal (LOBO, 2010). Embora o monitoramento em longo prazo com pontos distribuídos em uma rede de coleta de dados seja uma técnica mais adequada para o conhecimento da dinâmica atmosférica de uma caverna (CIGNA, 2002), diversos estudos no Brasil e no mundo têm utilizado os perfis atmosféricos espaço-temporais para a obtenção de respostas pontuais sobre determinado aspecto do espeleoclima, para a determinação de padrões sazonais - desde que sejam feitos com maior periodicidade, como nos trabalhos de Fernández-Cortés et al. (2006) e Milanolo e Gabrovsek (2009), por exemplo - ou para a identificação de impactos de origem antrópica, como em Fernández-Cortés et al. (2006), Lobo et al. (2009) e Lobo e Zago (2010).

Nesse sentido, o presente artigo apresenta os resultados da realização de dois perfis atmosféricos multiparamétricos na caverna Santana, com o uso das seguintes variáveis: temperatura do ar, umidade relativa do ar, concentração de gás carbônico $\left(\mathrm{CO}_{2}\right)$ e pressão atmosférica. O objetivo central do estudo foi fornecer suporte para o zoneamento higrotérmico do espeleoclima da caverna, bem como identificar zonas mais susceptíveis aos impactos da visitação turística, já que a Santana está entre as cavernas mais visitadas do país.

\section{CARACTERIZAÇÃO DA ÁREA DE ESTUDO}

A caverna Santana está localizada na área cárstica do vale do Ribeira, Sudoeste do Estado de São Paulo, município de Iporanga (Figura 1). Embora seu acesso seja feito pela ressurgência do rio Roncador, no interior do Parque Estadual Turístico do Alto Ribeira (PETAR), parte dos quase $10 \mathrm{~km}$ de condutos subterrâneos que as foram e o curso d'água que é o seu principal formador - o córrego Mendes - e o seu respectivo sumidouro - a caverna Pérolas - estão fora dos limites da Unidade de Conservação.

O clima na região do PETAR é meridional permanentemente úmido, controlado por massas tropicais e polares. A atuação das Massas Polares Atlânticas é mais significativa $(60 \%)$ do que a das Massas Tropicais Atlânticas (40\%). A sua unidade rítmica se caracteriza pela elevada frequência de penetração de massas polares e passagens frontais, em todas as estações do ano (MONTEIRO, 1973). A circulação atmosférica regional possui um ritmo tipicamente irregular, conforme os regimes pluviais, em uma área de influência oceânica secundária. o intervalo de tempo compreendido entre dezembro e fevereiro é, historicamente, mais chuvoso ( $33 \%$ do total das chuvas anuais), enquanto que o período entre junho e agosto é o mais seco (18\% do total). A precipitação média anual é de $1.500 \mathrm{~mm}$ - atingindo valores entre $100 \mathrm{~mm}$ e $300 \mathrm{~mm}$ em um período de $24 \mathrm{~h}$-, enquanto a temperatura média anual varia entre $19^{\circ} \mathrm{C}$ e $21{ }^{\circ} \mathrm{C}$ (GUTJAHR; TARIFA, 1993). A precipitação elevada se justifica pela alternância de atuação de diversos sistemas atmosféricos, com destaque para o Anticiclone Polar Atlântico, o Sistema Tropical Continental, as Frentes Polares e o Anticiclone Tropical Atlântico (GUTJAHR; TARIFA, 1995). 
A umidade relativa do ar (UR) é influenciada pela floresta atlântica, ficando próxima dos índices de saturação (100\%) durante o ano todo, com flutuações diárias geradas pela insolação. Não somente a floresta atlântica influencia na UR e na temperatura ambiente, mas também a compartimentação geomorfológica. A região da caverna Santana é composta por uma sequência de fundos de vales, formados por poligonais fechadas - típicas em áreas cársticas -, que conservam bolsões de ar em seu interior, caracterizando típicos microclimas.

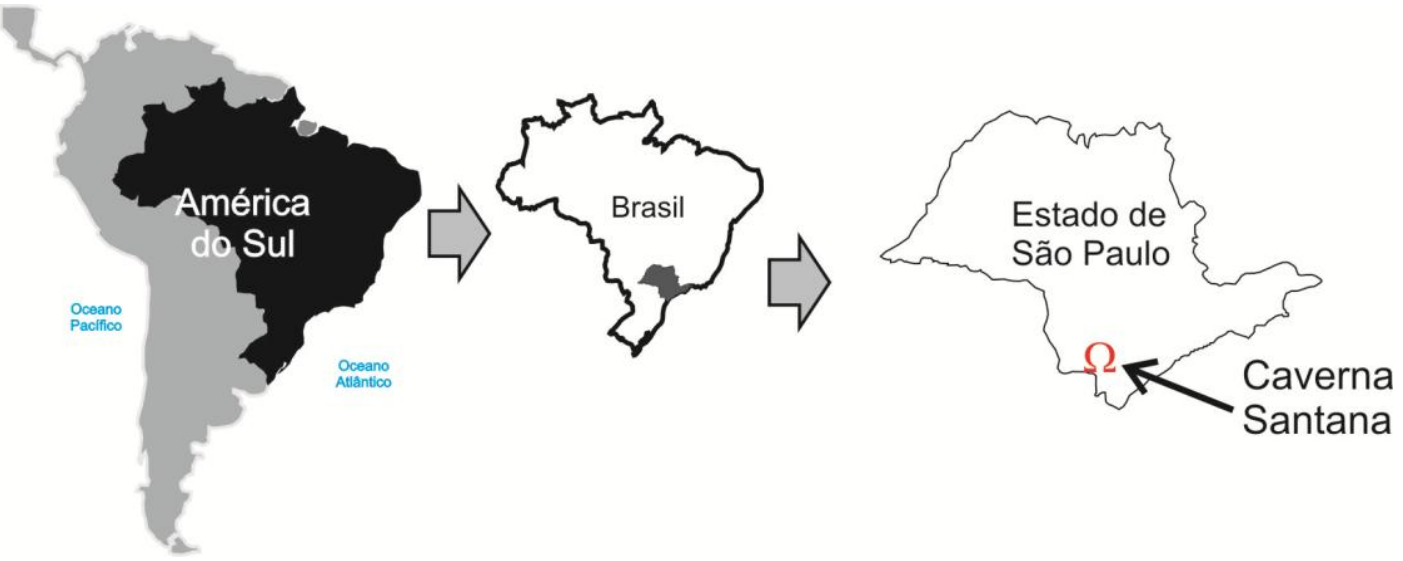

Figura 1. Localização relativa da caverna Santana no Estado de São Paulo

Por fim, vale ressaltar que a caverna Santana, assim como as outras cavernas abertas ao uso público na região do PETAR, em conjunto com suas cachoeiras, rios e a própria vegetação, compõem um grupo de recursos naturais que estão entre os mais relevantes atrativos para o ecoturismo no Estado de São Paulo. Nas últimas décadas, a visitação na caverna Santana tem sido da ordem de 20.000 visitantes/ano.

\section{MATERIAIS, MÉTODOS E ETAPAS DA PESQUISA}

O desenvolvimento das pesquisas de campo foi realizado nos anos de 2010 e 2011. Na ocasião, foi desenvolvido um monitoramento higrotérmico em 13 pontos distintos da caverna Santana, para caracterização atmosférica sazonal (LOBO, 2011a). Para complementar esta baixa densidade espacial, adotou-se um procedimento amostral complementar, a realização de perfis atmosféricos, a exemplo dos trabalhos de Fernández-Cortés et al. (2006) e de Milanolo e Grabrovsek (2009).

A perfilagem atmosférica permitiu a geoespacialização dos resultados, por meio de procedimentos de interpolação de dados, gerando com isto um episódio espacialmente delimitado e temporalmente variável. A variação temporal depende tanto do tempo de coleta de cada variável quanto da quantidade de pontos pré-estabelecidos. Na caverna Santana, foram estabelecidos 75 pontos de coleta (Figura 2), considerando as variáveis temperatura e umidade relativa do $\mathrm{ar}, \mathrm{CO}_{2}$ e pressão atmosférica. Os pontos foram concentrados no setor mais complexo de galerias do trecho inicial da caverna, área aberta ao uso turístico. Esta opção se deu em função de dois fatores: I) o enfoque do estudo, que possuía interface com o turismo na caverna Santana; e II) a dificuldade de se 
fazer o levantamento de campo no restante da caverna, formada predominantemente por galerias alagadas.

Com estas características, a realização de cada perfil durou aproximadamente $8 \mathrm{~h}$, já que é necessário aguardar a estabilização dos sensores entre uma leitura e outra, para evitar que os dados denotassem viés amostral ou tendências irreais. Outro cuidado tomado foi o distanciamento do sensor durante o processo de estabilização, para que a presença do pesquisador não interferisse nos valores de temperatura e concentração de $\mathrm{CO}_{2}$, principalmente. As características gerais do instrumento multifunção utilizado para a avaliação dos atributos atmosféricos estudados são apresentadas na Tabela 1.

Tabela 1. Características técnicas dos instrumentos do monitoramento exploratório

\begin{tabular}{lccccc}
\hline \multicolumn{1}{c}{ Instrumento } & Marca/Modelo & Memória & Variável & Precisão & Acurácia ${ }^{1}$ \\
\hline Multifunção & Testo 435 & 10.000 & & & \\
Sonda & Sonda IAQ & - & $\mathrm{T}$ & $0,1{ }^{\circ} \mathrm{C}$ & $0,3{ }^{\circ} \mathrm{C}$ \\
multiparâmetro & & & UR & $0,1 \%$ & $2 \%$ \\
& & & PA & $0,1 \mathrm{hPa}$ & $3 \mathrm{hPa}$ \\
& & $\mathrm{CO}_{2}$ & $0,1 \mathrm{ppm}$ & $\begin{array}{c}50 \mathrm{ppm}(2 \% \\
\text { do vol. })\end{array}$ \\
\hline
\end{tabular}

${ }^{1}$ Valores divergentes do catálogo do fabricante, definidos em certificados de calibração.

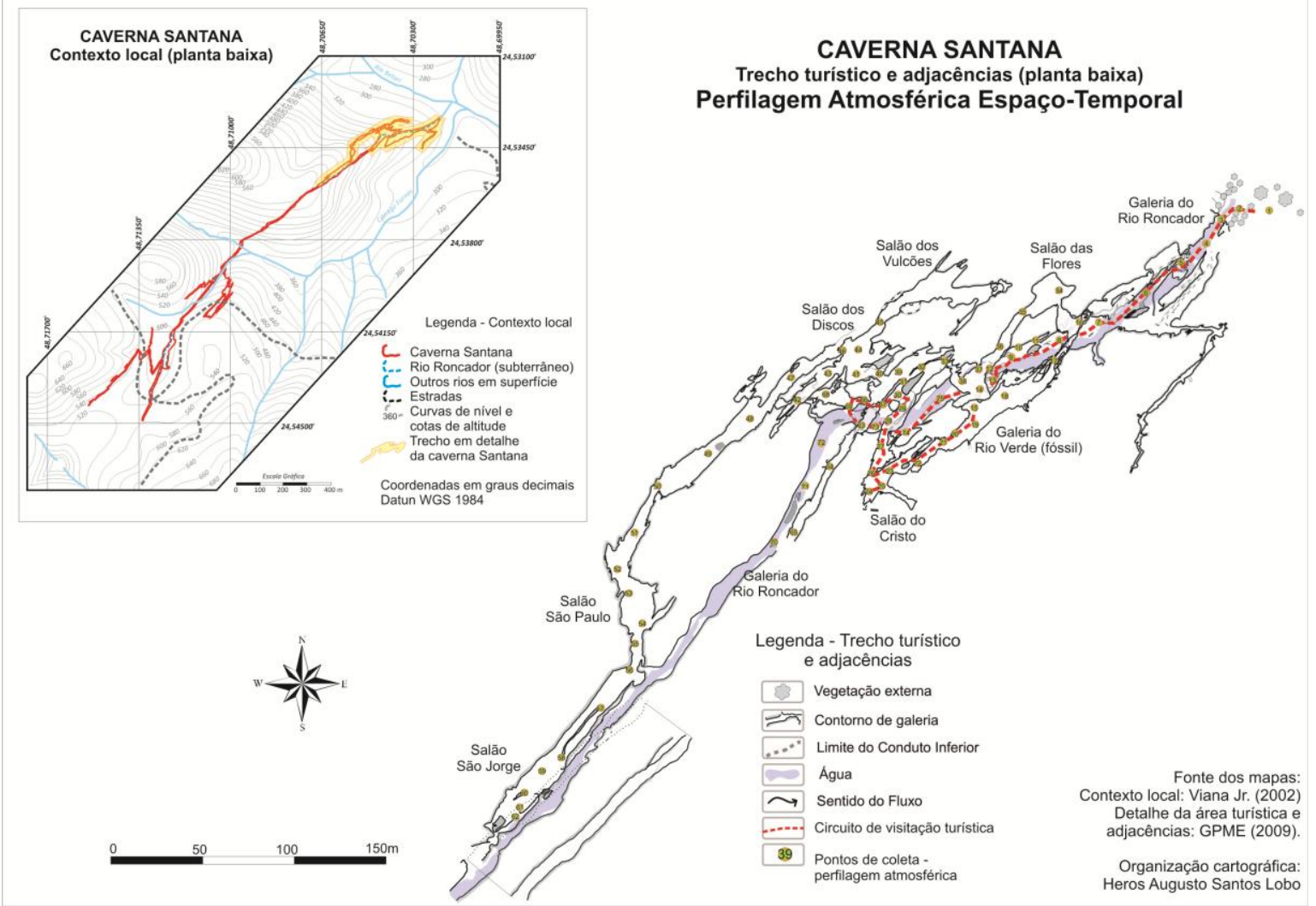

Figura 2. Distribuição dos pontos de perfilagem atmosférica na caverna Santana 
Foram realizados dois perfis espaço-temporais multivariados na caverna Santana, sendo um em abril de 2010 e outro em Janeiro de 2011. Os dados coletados foram interpolados com o uso de algoritmos no aplicativo Surfer ${ }^{\circledR}$ para a temperatura do ar, pressão atmosférica e $\mathrm{CO}_{2}$.

A realização dos perfis denotou certos cuidados, para evitar a geração de dados intermediários que destoassem da realidade da caverna Santana. Alguns problemas podem ser gerados na interpolação de dados atmosféricos em cavernas, como descrito por Lobo (2011b). A Figura 3 ilustra estas situações problemáticas, por meio de três exemplos em modelos teóricos de cavernas.

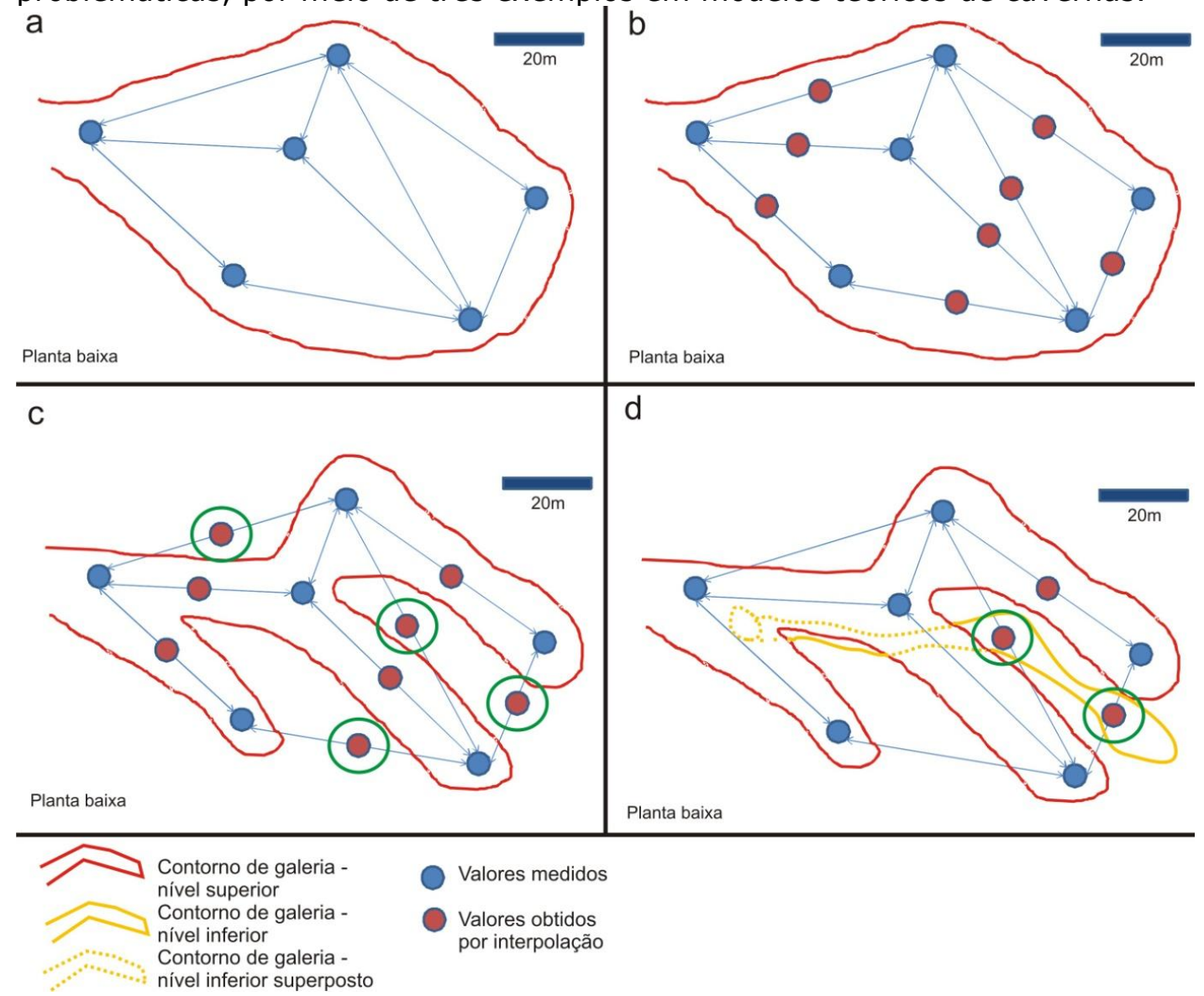

Figura 3. Espacialização dos problemas na interpolação de dados atmosféricos em cavernas (baseado em Lobo, 2011b)

O primeiro exemplo demonstrado (Figura 3a) ilustra uma situação de uma caverna com amplos salões internos e os respectivos pontos de coleta de dados atmosféricos (pontos azuis). Quanto é feita a interpolação, valores intermediários são gerados (pontos vermelhos - Figura 3b), permitindo a geração de isolinhas e respectivos gradientes de variação dos valores aferidos (ex.: isotermas e zonas térmicas). Situações como estas não requerem maiores 
cuidados, exceto pela seleção do algoritmo de interpolação mais adequado para cada situação.

No entanto, muitas das cavernas são formadas por redes complexas de galerias (Figura 3c), alterando totalmente esta realidade. Nestes casos, pode ocorrer de alguns pontos de coleta localizados em galerias paralelas, mas sem comunicação direta, interferirem na interpolação de outras galerias, gerando valores intermediários em áreas inexistentes de caverna (intra-rocha, destacados com círculos verdes), bem como isolinhas (isotermas, isógradas, isoigras) e gradientes de variação artificiais. Em casos mais complexos, a existência de galerias sobrepostas (Figura 3d) faz ainda com que valores de um nível de galerias interfiram nos valores gerados em outro nível (destacados em verde), alterando totalmente o padrão atmosférico do ambiente. A solução apontada por Lobo (2011b) para estes casos é gerar diversos perfis de interpolação, por trechos ou níveis de galerias, e depois fazer a junção entre eles em um único mapa. Esta etapa foi realizada para o presente trabalho, considerando que a caverna Santana é composta por cinco níveis de galerias e diversos trechos paralelos entre si, o que pode ser parcialmente observado na Figura 2. As primeiras interpolações geradas durante o processo apresentaram este problema de "invasão" de valores entre galerias, o que é demonstrado na Figura 4.

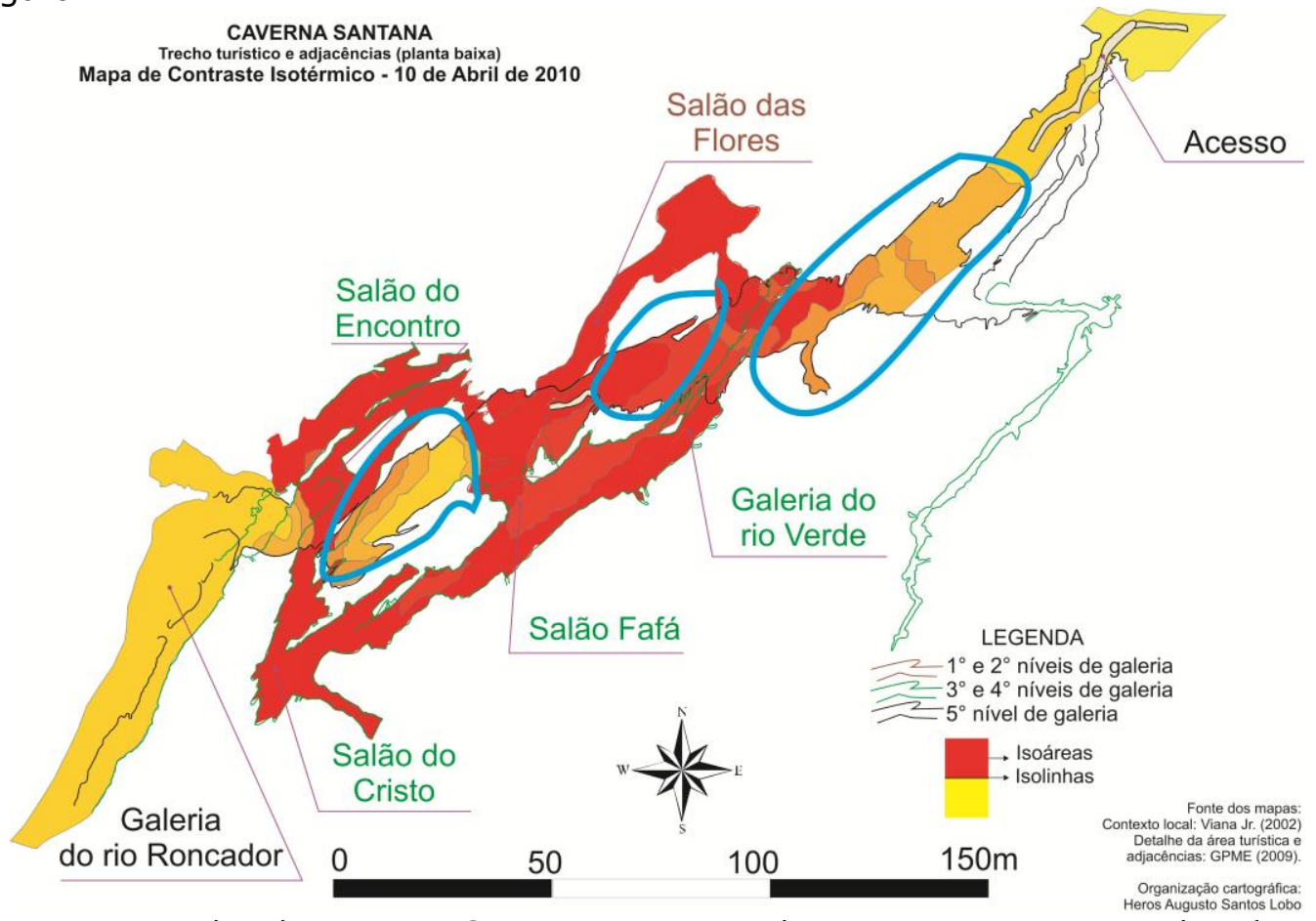

Figura 4. Trecho da caverna Santana contrastando a temperatura mais elevada em galerias superiores (vermelho) e temperaturas mais frias na galeria do rio (em amarelo e laranja). Os excessos de semitons de laranja nos trechos circulados em azul foram gerados por extrapolação estatística, culminando em zonas térmicas que não correspondem à realidade da galeria do rio. Fonte: modificado de Lobo (2011b). 
A elaboração dos perfis foi feita com o uso de três algoritmos, a título de teste: triangulação linear; superfícies de tendência ( $3^{a}$ à $5^{a}$ ordem) e krigagem ordinária. Destes, os que apresentaram os resultados mais coerentes e melhor ajuste à realidade espacial da caverna Santana foram a superfície de tendência de segunda ordem para a temperatura (Equação 1) e a triangulação linear para a pressão atmosférica e o gás carbônico (Equação 2).

$$
\begin{aligned}
& z_{i}(X, Y)=\left[a_{0}+a_{1} x_{i}+a_{2} y_{i}+a_{3} x_{i}^{2}+a_{4} x_{i} y_{i}+a_{5} y_{i}^{2}+\ldots\right]+e_{i}\left(x_{i}, y_{i}\right) \\
& Z^{*}=\sum_{i=1}^{N} \lambda_{i} Z_{i}
\end{aligned}
$$

Na superfície de tendência, $z_{i}(X, Y)$ é a variável mapeada, em função das variáveis $x_{i}$ e $y_{i}$, e onde $e_{i}$ representa a fonte não sistemática de variação, os resíduos (LANDIM, 2003). Na triangulação linear, o valor de um ponto predito $Z^{*}$ corresponde à somatória dos produtos entre os valores obtidos das variáveis em pontos conhecidos $Z_{i}$ e os respectivos pesos calculados $\lambda_{i}$ para cada ponto $i$, variando de 1 até $N$ (LANDIM et al., 2002).

As superfícies de tendência permitem a identificação de pequenas flutuações locais que, por vezes, podem ser mascaradas por padrões mais regionais (LANDIM, 2003). As vantagens no uso da triangulação linear são sua fidelidade e eficiência para uma visualização rápida dos dados. Além disso, ela é recomendada por Landim (2000) quando os valores estimados são necessários apenas dentro da área amostrada. Esta característica é de grande utilidade em cavernas, onde o confinamento espacial se configura como um limitante natural para os resultados da interpolação. Em testes anteriores, na gruta do Morro Preto, em Iporanga-SP (LOBO et al., 2009) e na gruna do Penhasco, em Buritinópolis-GO (LOBO; ZAGO, 2010), esta questão não foi enfrentada, dado que as cavernas são formadas por um grande salão único, ao contrário da caverna Santana.

\section{RESULTADOS E DISCUSSÃO}

Iniciando a exposição dos resultados, a umidade relativa do ar foi o parâmetro que apresentou a menor variação no ambiente. No perfil de abril de 2010, no outono, todos registros de umidade relativa foram em 99,9\%. No perfil de janeiro de 2011, no verão, apenas o ponto 1 , fora da caverna e distante aproximadamente $50 \mathrm{~m}$ de sua entrada, apresentou um valor de $71,1 \%$, e todos os demais também em $99,9 \%$. Com isso, não foram realizados perfis atmosféricos para a umidade relativa do ar (isoigras), pela baixa variabilidade do parâmetro.

Estes índices elevados de umidade relativa se explicam tanto por fatores climáticos regionais, pela posição espacial da caverna e pela presença do rio Roncador em seu interior, além de intenso processo de percolação nas galerias superiores, mantendo a caverna fisicamente ativa e constantemente úmida. Estudos anteriores na caverna Santana (e.g. VIANA Jr., 2002; SCALEANTE, 2003; LOBO et al., 2009) apresentaram resultados semelhantes, com variação 
da umidade relativa do ar no interior da caverna apenas em dias muito quentes e sem chuva, e ainda assim, apenas nos primeiros metros da galeria de acesso à caverna.

Para a temperatura do ar, a exposição dos resultados obtidos se inicia com os mapas de isotermas (Figuras 5 e 6), elaboradas com algoritmos de superfície de tendência.
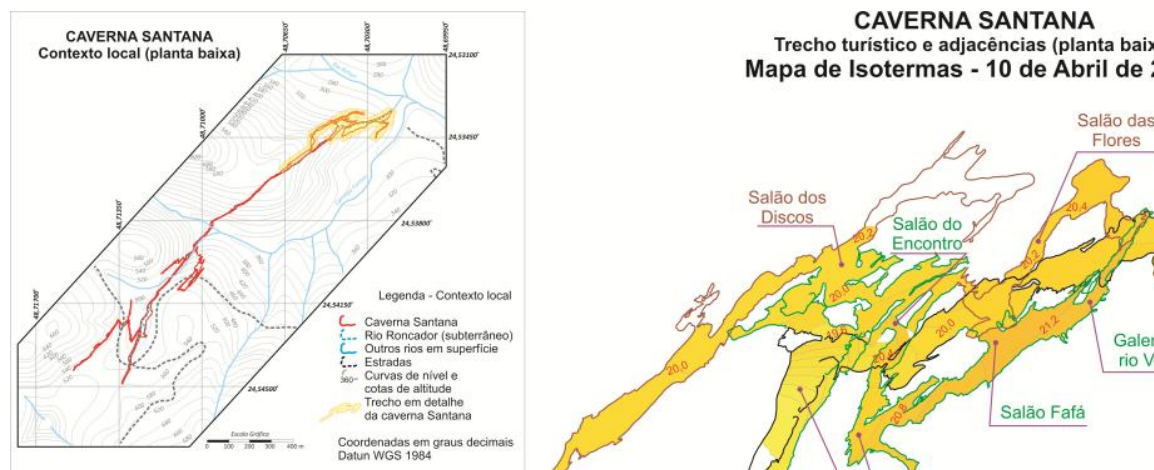

alăo dos

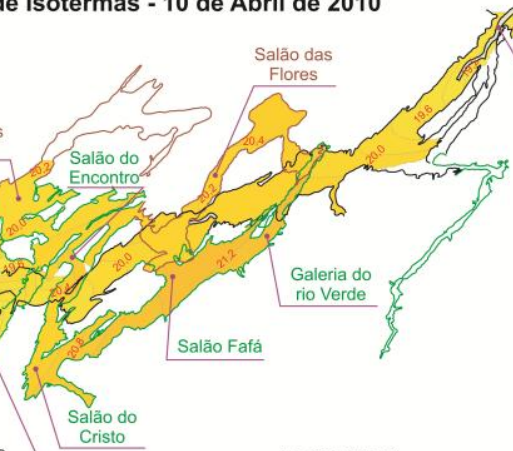

aleria

Cristo

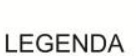

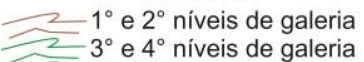
$5^{\circ}$ nivel de galeria
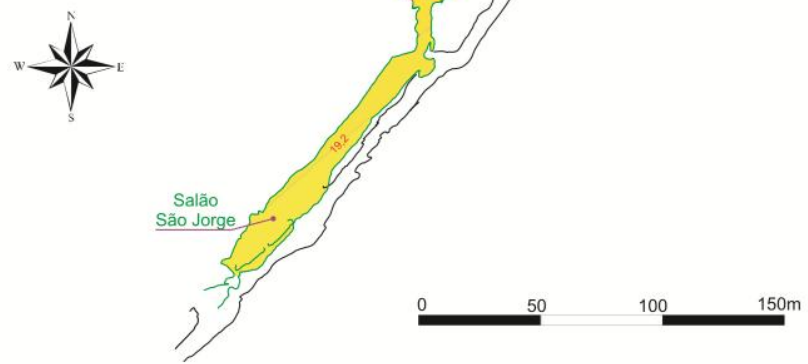

Figura 5. Mapa da superfície de tendência de segunda ordem de isotermas (10 de abril de 2010) 


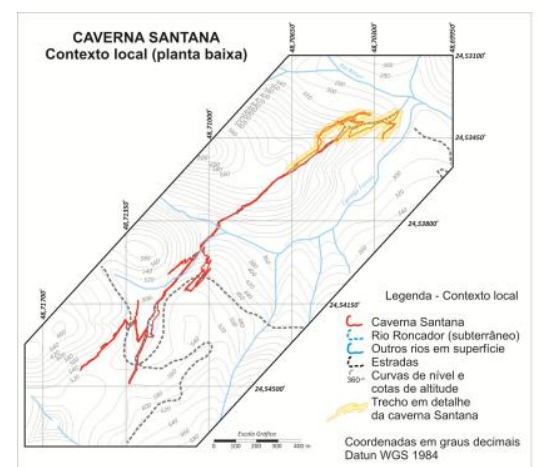

\section{CAVERNA SANTANA}

Trecho turistico e adjacências (planta baixa)

Mapa de Isotermas - $1^{\circ}$ de Janeiro de 2011

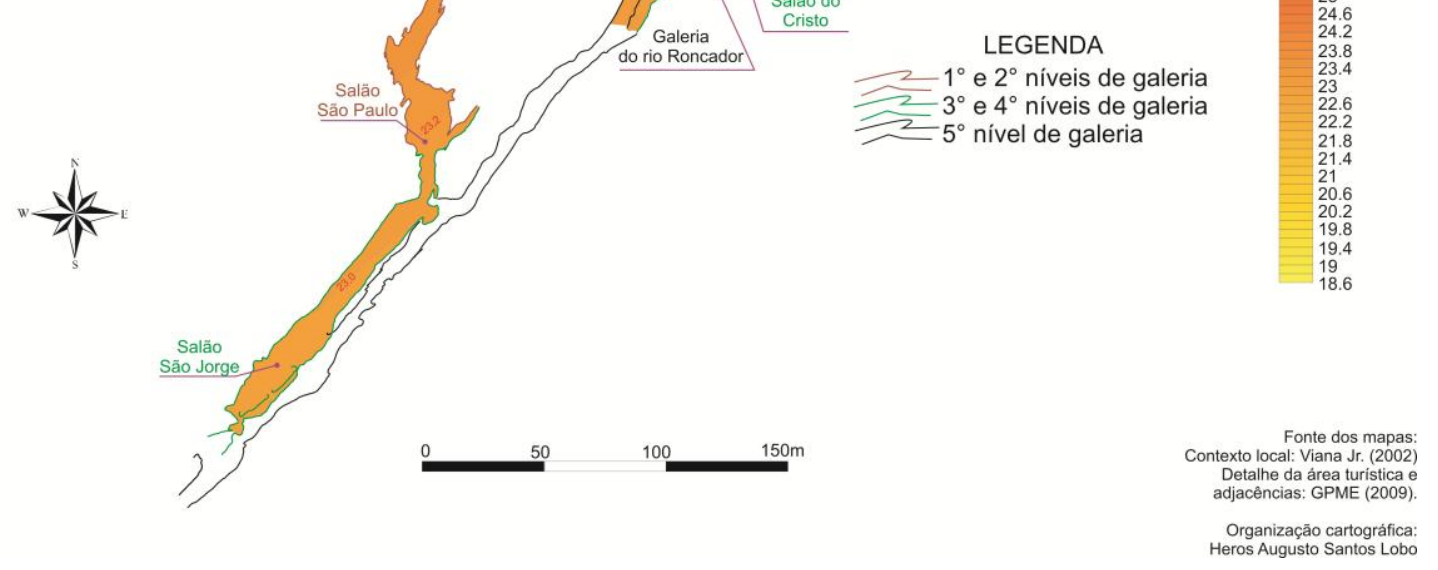

Figura 6. Mapa da superfície de tendência de segunda ordem de isotermas $\left(1^{\circ}\right.$ de janeiro de 2011) 
As figuras ilustram grandes diferenças entre os dois perfis, os quais precisam ser contextualizados, no espaço e, principalmente, no tempo. O intervalo médio de 8 horas para a coleta dos dados do perfil é um fator limitante para uma compreensão espacial estática das isotermas. Isto porque o tempo decorrido entre o início e o fim da realização de cada perfil é suficiente para que alterações atmosféricas tenham decorrido, modificando a condição aferida dos pontos do início da coleta. Trata-se, portanto, de uma limitação metodológica inerente ao processo desenvolvido, que não inviabiliza os dados, mas limita sua utilização e interpretação para determinadas situações.

A contextualização dos dados também considera a diferença de estações do ano em que foram registrados. Enquanto o perfil da Figura 4 foi feito no mês de abril, no outono, uma estação normalmente mais fria, o da Figura 5 foi feito em janeiro, no auge do verão. Desta forma, é de se esperar resultados totalmente distintos, como um padrão geral de temperaturas mais amenas no perfil de abril e de valores relativamente maiores no perfil de janeiro.

Embora registrados em épocas diferentes, os dados apresentam algumas semelhanças do ponto de vista qualitativo. Em ambos os perfis, os registros nas galerias superiores são de temperaturas mais elevadas que a galeria do rio. Esta situação fica ainda mais evidente nos salões Flores, Rio Verde e, em grau um pouco menor, na região dos salões São Paulo e São Jorge. Este resultado, em conjunto com dados contínuos de monitoramento (LOBO, 2011a) permite classificar o modelo geral de circulação de ar conforme a classificação publicada em Cigna (1967, 2004) e Eraso (1969), denominado warm trap. Literalmente, trata-se de uma armadilha para a captura do ar quente, que em função dos padrões físicos das galerias e da circulação do ar, se acumula nas galerias superiores da caverna (Figura 7).
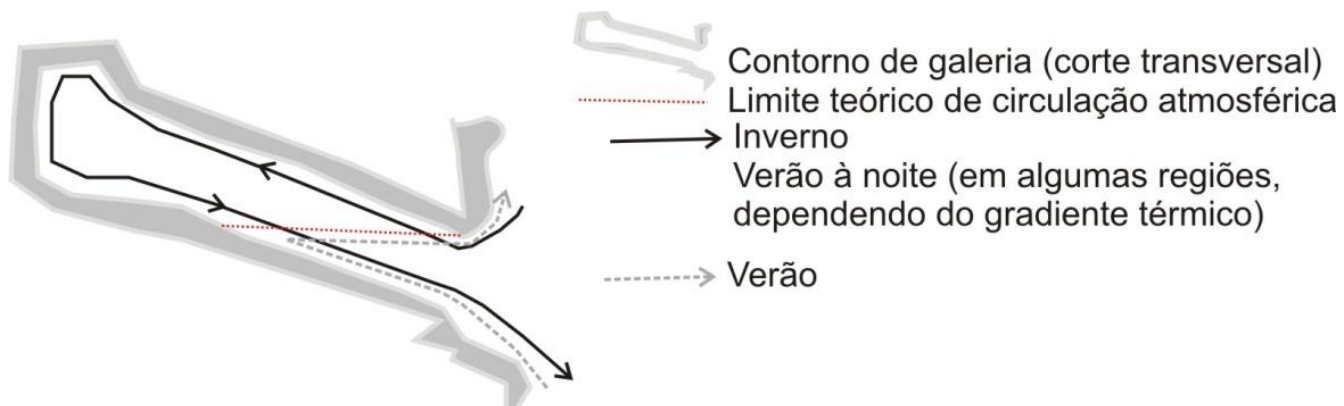

Verão

Figura 7. Modelo geral de circulação de ar em cavernas do tipo warm trap (CIGNA, 1967; 2004; ERASO, 1969).

Outro aspecto registrado é que o gradiente térmico externo não se propaga muito além das primeiras dezenas de metros da galeria do rio, o que é mais nítido no perfil da Figura 6 , no verão. No perfil de outono (Figura 5) esta discrepância térmica é menor, o que também se explica pelo fato de que os registros na galeria do rio e na parte externa foram feitos já à noite, após as $19 \mathrm{~h}$, quando as temperaturas gerais são mais amenas.

Se as superfícies de tendências das Figuras 5 e 6 permitem uma primeira visualização de distintos padrões térmicos em função da época do ano, esta 
diferenciação fica ainda mais evidente por meio da estatística descritiva dos dados por trechos da caverna Santana (Figura 8).

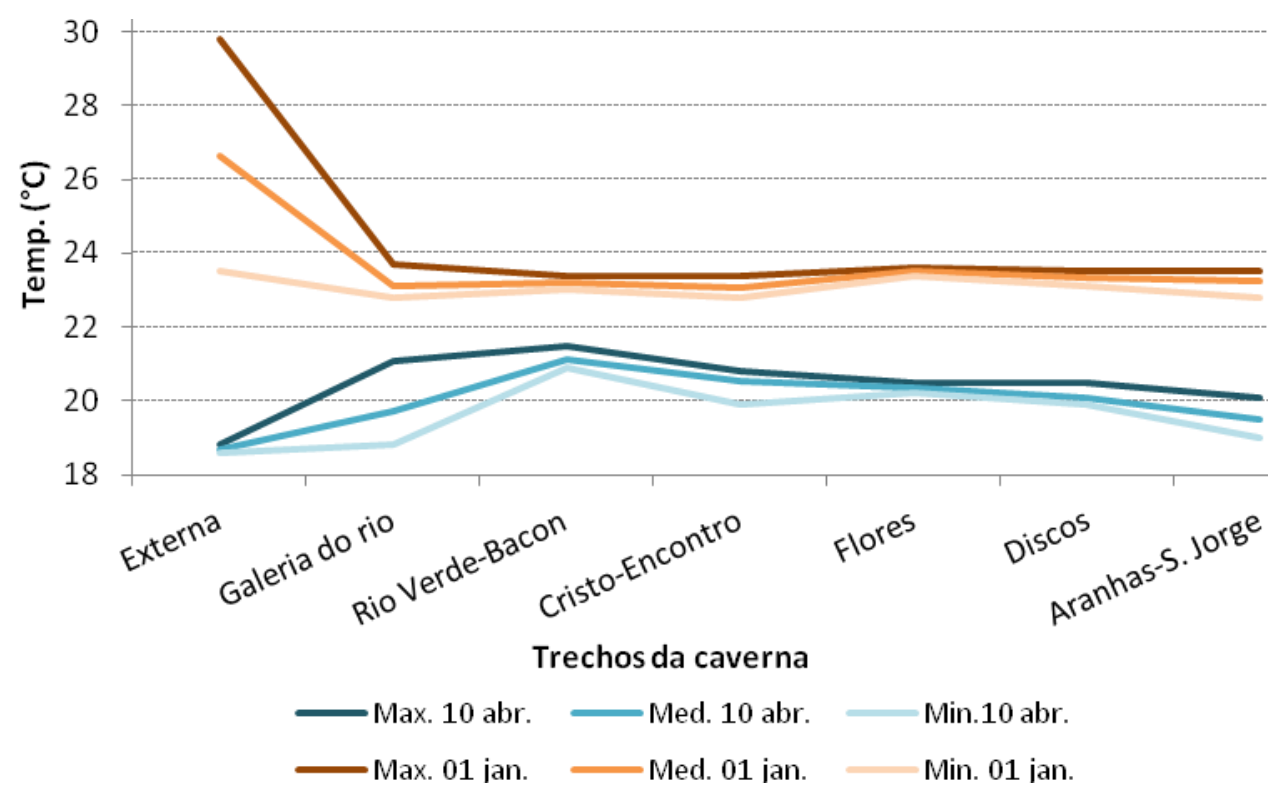

Figura 8. Temperaturas máximas, médias e mínimas do ar, por trechos da caverna Santana

As temperaturas registradas no perfil de 10 de abril de 2010 foram menores que as do dia $1^{\circ}$ de janeiro de 2011 , mesmo nas máximas registradas. As diferenças são observadas em todos os trechos da caverna e na área externa. Três trechos em particular chamam a atenção na Figura 8.

$\mathrm{Na}$ área externa, as diferenças registradas nas máximas dos dois perfis ocorrem principalmente em função do horário em que foram feitas: durante a noite em 10 de abril e no meio da tarde em $1^{\circ}$ de janeiro. Esta condição explica a amplitude térmica maior do segundo perfil, de $6,3^{\circ} \mathrm{C}$ em oposição aos $0,2{ }^{\circ} \mathrm{C}$ do primeiro. Durante o dia, a maior temperatura do ambiente externo diminui gradativamente em direção ao interior da caverna, o que se percebe no perfil atmosférico. A temperatura mais elevada $\left(29,8^{\circ} \mathrm{C}\right)$ foi aferida no ponto externo mais distante da ressurgência do rio Roncador (acesso da caverna), enquanto a mínima $\left(23,5^{\circ} \mathrm{C}\right)$ foi quase em sua entrada.

$\mathrm{Na}$ galeria do rio Roncador, houve maior amplitude térmica em 10 de abril $(2,3$ $\left.{ }^{\circ} \mathrm{C}\right)$ do que em $1^{\circ}$ de janeiro $\left(0,9^{\circ} \mathrm{C}\right)$. Neste caso, a variação é atribuída à dinâmica atmosférica diferenciada nas distintas épocas do ano. Os valores mais elevados do perfil de outono $\left(21,1^{\circ} \mathrm{C}\right)$ são de pontos mais superiores na galeria, como no Cavalo e na escada que sobre para o salão Fafá (espeleotema Peru). Estes pontos mais elevados estão mais sujeitos a uma influência maior das camadas superiores de ar mais quente dentro da caverna, sobretudo em dias mais frios. No perfil de verão esta diferença não se evidencia, pois toda a atmosfera estava mais aquecida, com a máxima no trecho chegando a $23,7{ }^{\circ} \mathrm{C}$ (influência direta do meio externo, sendo esta temperatura registrada próxima 
a ressurgência) e com $23,2^{\circ} \mathrm{C}$ no espeleotema Peru $-2,1^{\circ} \mathrm{C}$ a mais do que o registrado no mesmo ponto no mês de abril.

Por fim, o setor Aranhas - São Jorge, que inclui o salão São Paulo. Enquanto no perfil de outono sua temperatura foi relativamente mais baixa que as demais galerias da caverna - tanto nas máximas quanto na média -, no perfil de verão sua temperatura foi mais próxima das demais galerias. No entanto, as variações são bastante sutis, tornando a realização de apenas dois perfis insuficiente para uma explicação mais conclusiva sobre os motivos destas diferenças.

Outro parâmetro aferido nos perfis foi a pressão atmosférica (Figura 9).

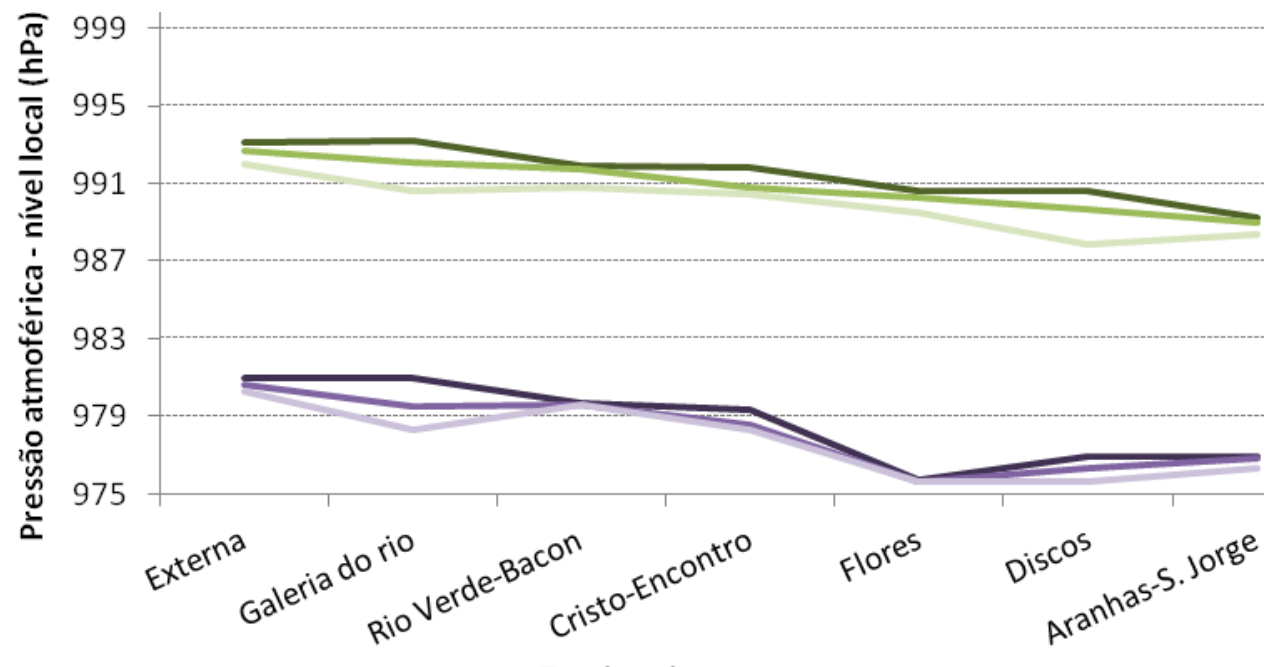

Trechos da caverna

Max. $10 \mathrm{abr}$. Med. $10 \mathrm{abr}=$ Min.10 abr.
Max. 01 jan. $\longrightarrow$ Med. 01 jan. $=$ Min. 01 jan.

Figura 9. Máximas, médias e mínimas do perfil de pressão atmosférica por trechos da caverna Santana

Embora as faixas de variação entre os perfis sejam diferentes entre si em aproximadamente 12 - $15 \mathrm{hPa}$, seus padrões de variabilidade são semelhantes. Tal fato é digno de nota, dado que os perfis foram feitos não somente em épocas distintas do ano, mas em diferentes horários do dia.

Ainda assim, as variações por trechos da caverna registradas na Figura 8 demonstram um padrão geral, com a pressão sendo mais elevada no ambiente externo e mais baixa à medida que se avança ao interior da caverna, com uma diferença de aproximadamente $4 \mathrm{hPa}$. A título de exemplo, a Figura 10 traz um mapa de isóbaras feita por triangulação, do perfil de outono (abril/2010). 


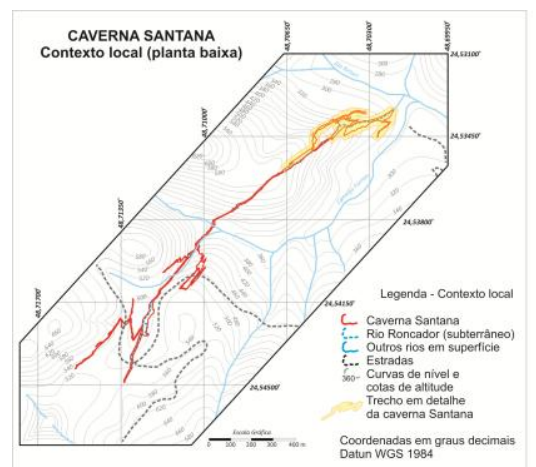

CAVERNA SANTANA Trecho turístico e adjacências (planta baixa) Mapa de Isóbaras - 10 de Abril de 2010
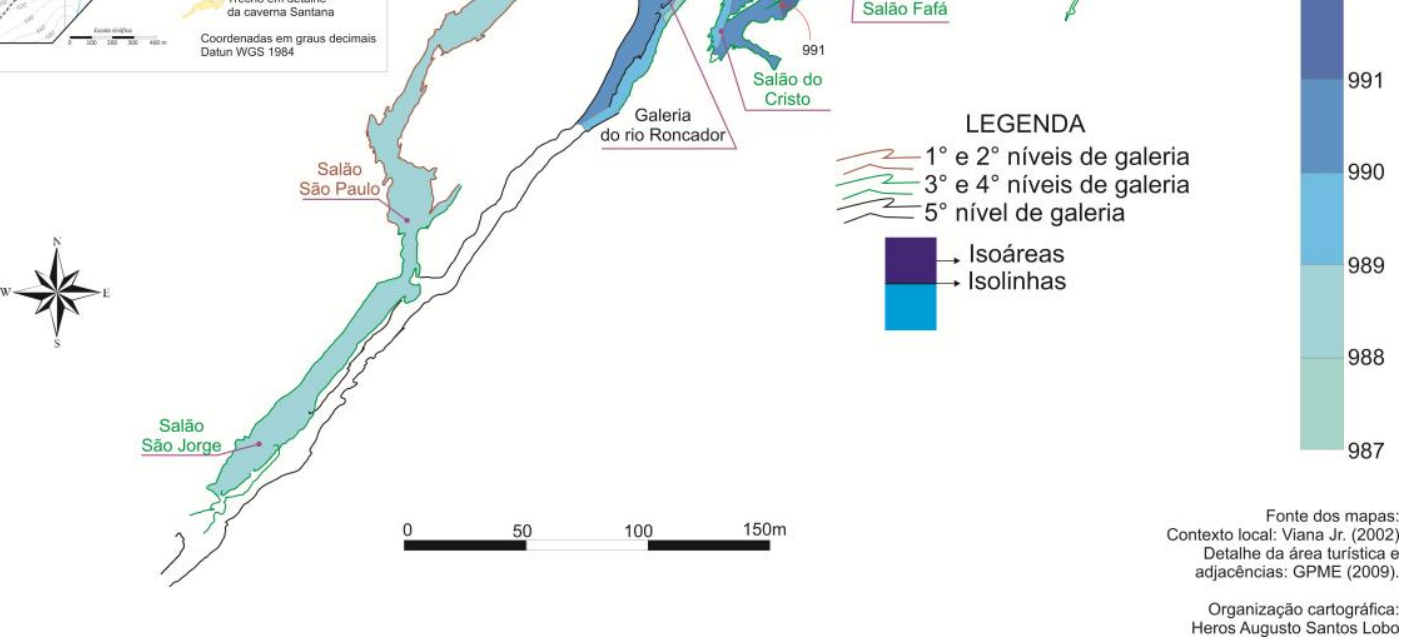

Figura 10. Mapa de isóbaras interpoladas por triangulação, do dia 10 de abril de 2010

A pressão atmosférica apresentou pequena variação no perfil feito em abril/2010, com mínima de 987,4 hPa no acesso ao salão dos Vulcões e máxima de $992,7 \mathrm{hPa}$ na galeria do rio, próxima ao acesso ao salão do Cavalo. Particularmente, em relação à máxima, a sua relação com os pontos periféricos na interpolação apresentou detalhamento demasiado nas isoáreas geradas por triangulação (Figura 10). Além disso, a triangulação apresenta excesso de isoáreas na galeria do rio em posição paralela ao conduto, o que foge à probabilidade de uma situação real.

Para $0 \mathrm{CO}_{2}$, os resultados tratados com o uso de algoritmo de triangulação são apresentados nas Figuras 11 e 12. 
ISSN: 1980-055x (Impressa) 2237-8642 (Eletrônica)

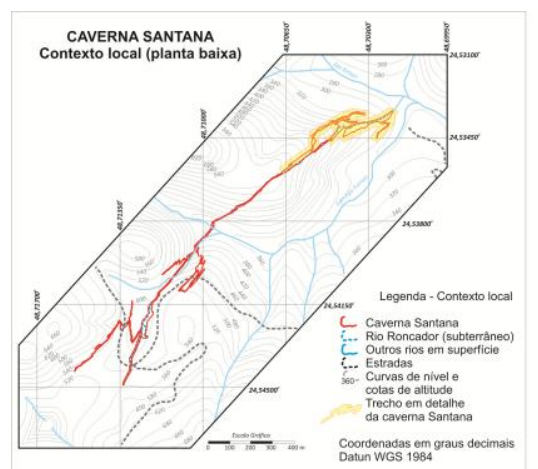

CAVERNA SANTANA

Trecho turistico e adjacências (planta baixa)

Mapa de Isoáreas de $\mathrm{CO}_{2}-10$ de Abril de 2010

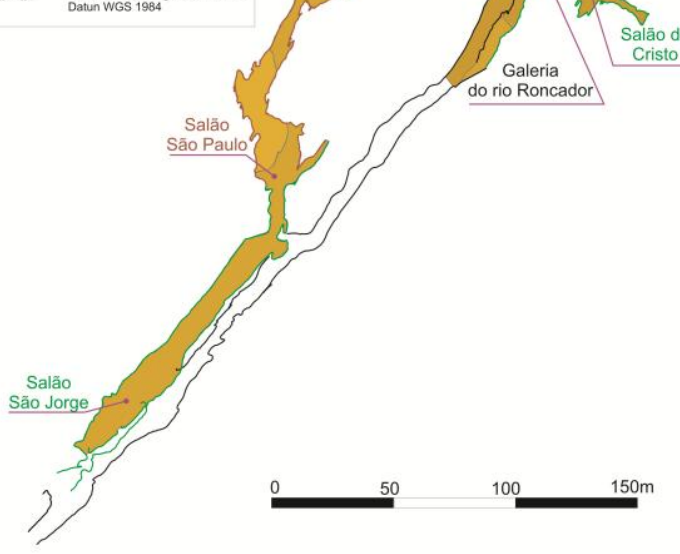

Salão Fafá

Galeria do

rio Verde

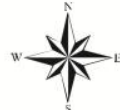

LEGENDA

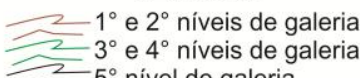

$\sqrt{2} 1^{\circ}$ e $2^{\circ}$ níveis de galeria
$24^{\circ}$ e $4^{\circ}$ niveis de galeria

Acesso

Escala (ppm)

1200

1150

1100

800

$25^{\circ}$ nivel de galeria

$\rightarrow$ Isoáreas

$\rightarrow$ Isolinhas

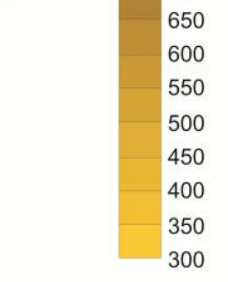

Fonte dos mapas:
Contexto local: Viana Jr. (2002) Detalhe da área turistica e

Figura 11. Mapa de Isoáreas de $\mathrm{CO}_{2}$ interpoladas por triangulação. De 10 de abril de 2010 


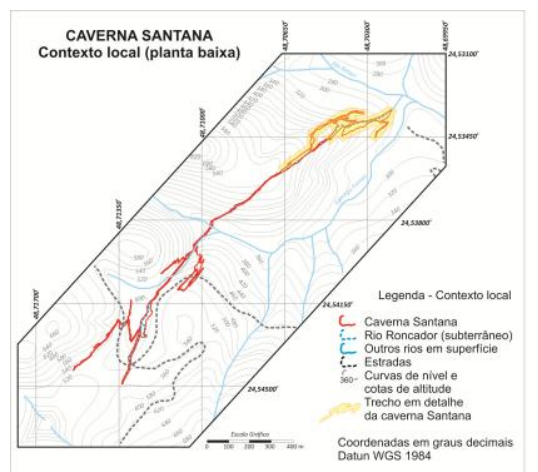

\section{CAVERNA SANTANA}

Trecho turistico e adjacências (planta baixa) Mapa de Isoáreas de $\mathrm{CO}_{2}-1^{\circ}$ de Janeiro de 2011
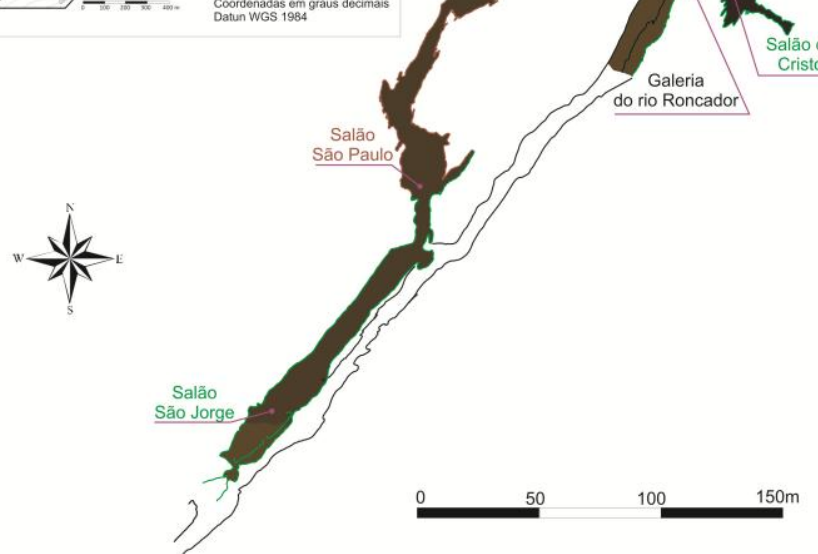

Salão Fafá

rio verde

$-1^{\circ}$ e $2^{\circ}$ niveis de galeria

$3^{\circ}$ e $4^{\circ}$ níveis de galeria

$25^{\circ}$ nivel de galeria

$\rightarrow$ Isoáreas

$\rightarrow$ Isolinhas

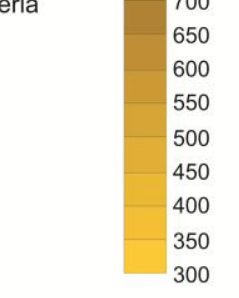

Figura 12. Mapa de isoáreas de $\mathrm{CO}_{2}$ interpoladas por triangulação, de $1^{\circ}$ de janeiro de 2011

$\mathrm{CO}_{2}$ apresentou um padrão qualitativo muito semelhante em ambos os perfis, com a concentração se elevando mais nas galerias superiores e trechos mais confinados da caverna. Este padrão comum é visualizado de forma mais nítida na Figura 13. Os valores mais elevados são encontrados nos salões Cristo, Encontro, Flores e Discos. No perfil de outono (Figura 11), a concentração no salão das Flores foi acima dos demais salões, com média de 861,6 ppm contra uma média geral do restante da caverna de 533,4 ppm - e máxima de 910 ppm.

No perfil de verão (Figura 12), a concentração geral de $\mathrm{CO}_{2}$ foi maior do que no outono. Enquanto no outono a média geral no interior da caverna foi de 588,1 ppm, no verão este valor atingiu 991,5 ppm. Na área externa a diferenciação não foi tão evidente, como média de 383 ppm no outono e 413 ppm no verão. A maior concentração média foi no salão das Flores, de 1095,7 ppm, seguida pelos trechos Cristo-Encontro (1077,6 ppm), Discos (1045,5 ppm) e AranhasSão Jorge $(1011,7 \mathrm{ppm})$. Entretanto, o maior valor absoluto foi registrado no salão do Cristo, com 1154 ppm. Deve-se ressaltar que este registro foi obtido durante o horário de visitação, com a presença de um grupo de nove visitantes 
no salão no momento da coleta - o que provavelmente interferiu no resultado. Nos salões Flores e Discos, as máximas registradas foram de, respectivamente, 1124 ppm e 1083 ppm - neste caso, sem a presença de visitantes.

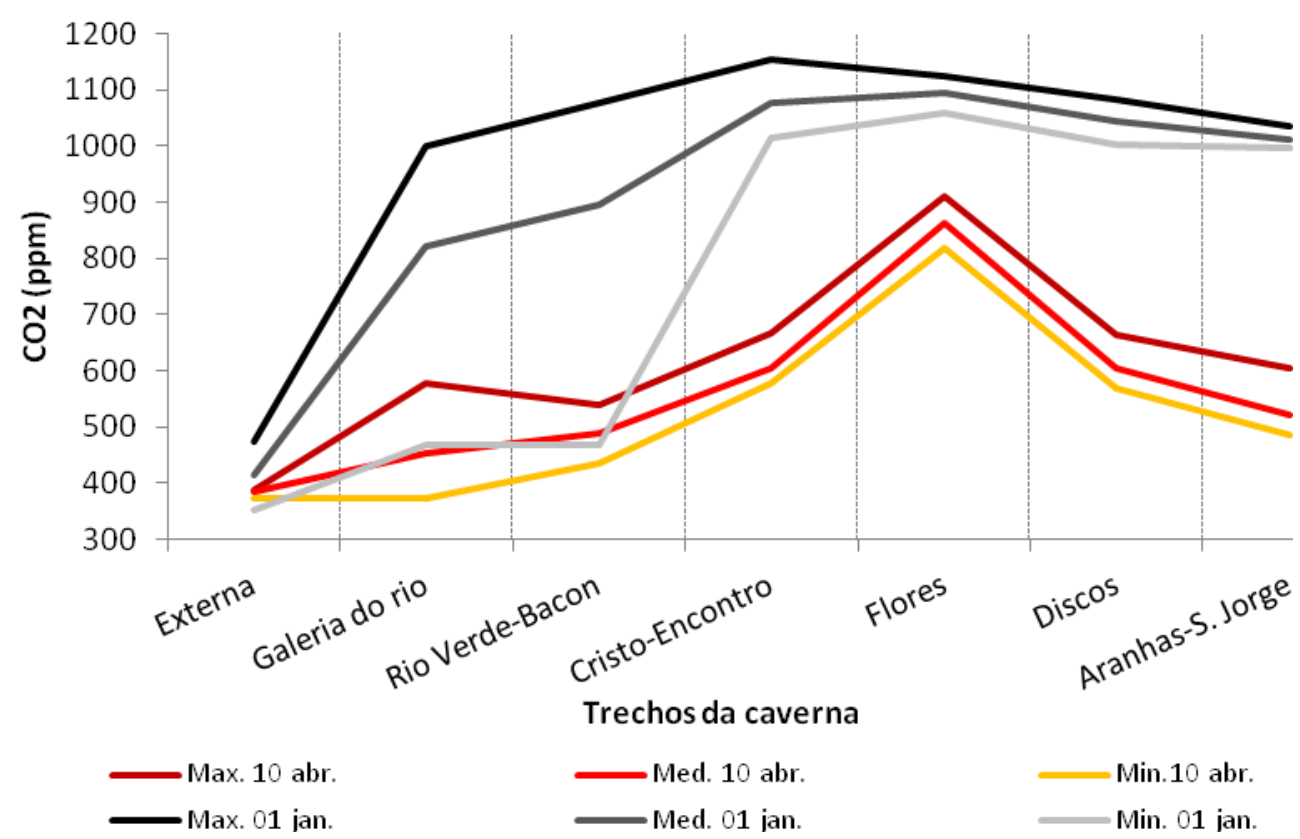

Figura 13. Máximas, médias e mínimas do perfil de $\mathrm{CO}_{2}$ por trechos da caverna Santana

Os valores obtidos para o $\mathrm{CO}_{2}$, maiores nas galerias superiores do que nas inferiores, a princípio, podem soar como contraditórios considerando a ideia geral que se difunde de que $\mathrm{o} \mathrm{CO}_{2}$ é mais pesado, portanto se acumularia em zonas mais profundas. Badino (2009) aborda esta questão com propriedade, demonstrando que a ausência de movimentação constante de ar é o grande fator de acúmulo de $\mathrm{CO}_{2}$, e não seu peso relativo. Os dados obtidos são coerentes com esta colocação, pois a concentração de $\mathrm{CO}_{2}$ foi sempre maior nas galerias com menor movimentação gasosa e sem visitação turística.

Teoricamente, poderia se esperar maior concentração de $\mathrm{CO}_{2}$ nas galerias com pouca movimentação de ar e com visitação, dado que a respiração humana libera $\mathrm{CO}_{2}$, fato já relatado na literatura (e.g. DRAGOVITCH; GROSE, 1990; LIÑÁN et al., 2008; FREITAS, 2010) e que pode ser observado em campo, quando da passagem de grupos de turistas pelos instrumentos de medição. Porém, com base na questão da movimentação mínima colocada por Badino (2009), acredita-se que a movimentação dos turistas seja um dos fatores que contribuem para que não haja acúmulos de $\mathrm{CO}_{2}$ nos trechos visitados tal como ocorre em suas imediações - galerias fósseis, com diversas restrições e mínima circulação de ar.

Por fim, é preciso considerar a relação entre os padrões observados e a visitação turística. Com base em estudos ANTERIORES (E.G. MANGIN; ANDRIEUX, 1988; LOBO; ZAGO, 2010), descartam-se as preocupações com alterações causadas pela visitação turística nos padrões de pressão atmosférica e umidade relativa do ar - neste último, exceto com o uso de carbureteiras, 
que alteram em demasia a temperatura e a umidade (LOBO; ZAGO, 2010). O enfoque então se concentra na temperatura e nas concentrações de $\mathrm{CO}_{2}$.

Sobre a temperatura, teoricamente a conformação da caverna Santana como uma warm trap é desfavorável, pois a tendência maior de fluxo de ar quente gerado pela visitação seria cumulativa para o interior da caverna e galerias superiores. No entanto, os diversos estudos conduzidos na caverna (SCALEANTE, 2003; LOBO, 2011a, entre outros) têm demonstrado a inexistência de um padrão efetivamente cumulativo térmico na caverna. A rápida dispersão das plumas térmicas geradas pela visitação, constatadas por Lobo (2011a) explicam adequadamente esta questão.

Sobre $\mathrm{O} \mathrm{CO}_{2}$, embora a concentração não seja significativamente maior nas áreas visitadas, os estudos apresentados em Lobo (2011a) demonstram uma possível existência de corrosão nos espeleotemas induzida por condensação, a qual poderia, em tese, estar com maior potencial corrosivo em função dos aumentos pontuais quando da passagem de visitantes. Assim, mantém-se a hipótese de dano ambiental nos espeleotemas em função do aumento na concentração de $\mathrm{CO}_{2}$ pela visitação, a ser mais bem investigada em pesquisas futuras, cujo enfoque deverá ser centrado na condensação induzida pela visitação face ao choque térmico gerado (aumento da temperatura do ar versus temperatura mais fria das rochas e espeleotemas), tal como já realizado por Freitas e Schmekal (2006) em cavernas no exterior.

\section{CONCLUSÕES}

O uso dos perfis atmosféricos em cavernas se demonstrou de grande utilidade no apoio à definição de padrões de circulação e acúmulo no ambiente, permitindo sua modelagem conceitual. No caso da caverna Santana, foi possível classificá-la como uma warm trap, com uma região mais quente nas galerias superiores. Também foi notada a maior concentração de $\mathrm{CO}_{2}$ nestas galerias, sobretudo nos trechos não visitados.

De um modo geral, embora as warm traps sejam padrões cumulativos de ar mais aquecido, não foram encontradas evidências de aumento da temperatura nas galerias superiores quando da passagem de turistas. A própria dinâmica do ambiente, bem como os volumes internos das galerias e salões, impedem esta dispersão, limitando os impactos atmosféricos da visitação aos trechos percorridos pelos turistas. $\mathrm{O}$ mesmo se aplica ao $\mathrm{CO}_{2}$, que embora apresente potencial corrosivo para os espeleotemas, não se demonstrou em valores alarmantes até o presente, ensejando pesquisas futuras com enfoque químico, que possam estudar a condensação nos espeleotemas durante a passagem de turistas. Assim, conclui-se que, dentro dos limites observados, o turismo não causa impactos irreversíveis ou demasiadamente significantes nos padrões gerais do espeleoclima da caverna Santana.

\section{REFERÊNCIAS}

BADINO, G. The legend of carbon dioxide heaviness. Journal of Cave and Karst Studies, Huntsville, v.71, n.1, p.100-107, 2009.

CIGNA, A.A. An analytical study of air circulation in caves. International Journal of Speleology, Bologna, v.3B, n.1/2, p.42-54, 1967.

CIGNA, A.A. Modern trend in cave monitoring. Acta Carsologica, Ljubljana, v.31, n.1, p.35-54, 2002. 
CIGNA, A.A. Climate of caves. In: GUNN, J. (Ed.) Encyclopedia of caves and karst science. London: Taylor \& Francis, 2004. p.467-475.

DRAGOVITCH, D.; GROSE, J. Impact of tourism in carbon dioxide levels at Jenolan caves, Australia: an examination of microclimatic constraints on tourist cave management. Geoforum, v.21, n.1, p.111-120, 1990.

ERASO, A. La corrosión climática en las cavernas. Boletín Geológico y Minero, v.80, n.6, p.564-581, 1969.

FERNÁNDEZ-CORTÉS， A.; CALAFORRA， J.M.; JIMÉNEZ-ESPINOSA， R.; SÁNCHEZMARTOS, F. Geostatistical spatiotemporal analysis of air temperature as an aid to delineating thermal stability zones in a potential show cave: implications for environmental management. Journal of Environmental Management, v.81, p.371383, 2006.

FREITAS, C.R. de. The role and the importance of cave microclimate in the sustainable use and management of show caves. Acta Carsologica, Postojna, v.39, n.3, p.477-489, 2010.

FREITAS, C.R. de; SCHMEKAL, A. Studies of condensation/evaporation processes in the Glowworm cave, New Zealand. International Journal of Speleology, Bologna, v.35, n.2, p.75-81, 2006.

GPME - GRUPO PIERRE MARTIN DE ESPELEOLOGIA. Mapa da caverna Santana. GPME, São Paulo, 2009. 1p.

GUTJAHR, M.R.; TARIFA, J.R. Critérios relacionados a compartimentação climática de bacias hidrográficas: a bacia do rio Ribeira de Iguape-SP. In: SIMPóSIO BRASILEIRO DE GEOGRAFIA FÍSICA APLICADA, 5, 1993, São Paulo. Anais. São Paulo: USP, 1993. p.447-449.

GUTJAHR, M.R.; TARIFA, J.R. A abordagem sinótica em estudos de compartimentação climática. In: SIMPósIo BRASILEIRO DE GEOGRAFIA FÍSICA APLICADA, 6, 1995, Goiânia. Anais do.... Goiânia: UFG, 1995. p.44-48.

LANDIM, P.M.B. Análise estatística de dados geológicos multivariados. Rio Claro: Lab. Geomatemática, 2000. 128 p.

LANDIM, P.M.B. Análise estatística de dados geológicos. 2.ed. Rio Claro: Edunesp, 2003. 253 p.

LANDIM, P.M.B.; MONTEIRO, R.C.; CORSI, A.C. Introdução à confecção de mapas pelo software surfer. Rio Claro: Laboratório de geomatemática, 2002. 29 p.

LIÑÁN, C.; VADILLO, I.; CARRASCO, F. Carbon dioxide concentration in air within the Nerja cave (Malaga, Andalusia, Spain). International Journal of Speleology, v.37, n.2, p.99-106, 2008.

LOBO, H.A.S. Histórico das pesquisas espeleoclimáticas em cavernas brasileiras. Espeleo-Tema, v.21, p.131-144, 2010.

LOBO, H.A.S. Estudo da dinâmica atmosférica subterrânea na determinação da capacidade de carga turística na caverna de Santana (PETAR, Iporanga-SP). 2011. 392 p. Tese (Doutorado em Geociências e Meio Ambiente) - Instituto de Geociências e Ciências Exatas, Universidade Estadual Paulista, Rio Claro. 2011a.

LOBO, H.A.S. Aplicações e limitações do uso de algoritmos de interpolação espacial no aplicativo Surfer ${ }^{\circledR}$ em perfis atmosféricos subterrâneos. In: RASTEIRO, M.A. (Ed.). CONGRESSO BRASILEIRO DE ESPELEOLOGIA, 31, Ponta Grossa. Anais. Ponta Grossa: SBE/GUPE, 2011b. p.521-526.

LOBO, H.A.S.; ZAGO, S. Iluminação com carbureteiras e impactos ambientais no microclima de cavernas: estudo de caso da lapa do Penhasco, Buritinópolis-Go. Geografia, Rio Claro, v.35, n.1, p.183-196, 2010.

LOBO, H.A.S.; PERINOTTO, J.A. de J.; BOGGIANI, P.C.; ZAGO, S. Eventos musicais causam impactos no microclima de cavernas? Avaliação das alterações na atmosfera subterrânea da gruta Morro Preto (PETAR, Iporanga-SP). Geonomos, Belo Horizonte, v.17, n.1, p.01-10, 2009. 
MANGIN, A.; ANDRIEUX, C. Infiltration et environnement souterrain, le role de I'eau sur les paramètres climatiques. Actes des Jounées Félix Trombe, Moulis, p.7995, 1988.

MILANOLO, S.; GRABROVSEK, F. Analysis of carbon dioxide variations in the atmosphere of Srednja Bijambarska cave, Bosnia and Herzegovina. BoundaryLayer Meteorology, v.131, p.479-493, 2009.

MONTEIRO, C.A. de F. A Dinâmica climática e as chuvas no Estado de São Paulo estudo geográfico sob forma de atlas. São Paulo: Universidade de São Paulo/Instituto de Geografia, 1973. 129 p.

SCALEANTE, J.A.B. Avaliação do impacto de atividades turísticas em cavernas. 2003. 82. p. Dissertação (Mestrado em Geociências) - Instituto de Geociências, Universidade Estadual de Campinas, Campinas. 2003.

VIANA JÚNIOR, O. Hidroquímica, hidrologia e geoquímica isotópica ( $\mathrm{O}$ e $\mathrm{H}$ ) da fácies de percolação vadosa autogênica, caverna Santana, Município de Iporanga, Estado de São Paulo. 2002. 113 p. Dissertação (Mestrado em Geoquímica) - Instituto de Geociências, Universidade de São Paulo, São Paulo. 2002. 